\title{
VASOTOMY IN THE TREATMENT OF CHRONIC SEMINAL VESICULITIS OF GONORRHEAL ORIGIN
}

\author{
By ABR. L. WOLBARST, M.D., New York City
}

CHRONIC seminal vesiculitis of gonococcal origin has been termed the "bête noire" of urogenital surgery, and rightly so. It is one of the most difficult conditions with which we have to deal.

The seminal vesicles are affected in more than half the cases during the first weeks of an antero-posterior infection. The symptoms are not generally recognised at the time because they are ascribed to acute prostatitis ; but the diagnosis usually can be made by rectal examination and the urine tests.

Because of inadequate and ineffective treatment in the acute stages, the infection becomes chronic and more or less intractable. The vesicle is converted into a closed sac, natural drainage ceases and the sac contents are removed only through its own contractions ; the ejaculatory duct is closed by a pus clot or by inflammatory swelling and the vesicle becomes, in fact, a stagnant pool, the " male pus tube," until through retrograde pressure of the contractions, the pus is forced back into the vas deferens and the epididymis. Gonorrheal epididymitis always is the result of an extension of the infection from the vesicles. Vesiculitis generally is bilateral, even though the symptoms may be unilateral.

As a source of focal infection, vesiculitis stands high. It has been demonstrated that the vesicles act as a focus for metastatic infection in arthritis, iritis, neuritis, neuralgia, indeterminate pyrexia, backache, neurasthenia and many other functional disturbances. Furthermore, vesiculitis often has been mistaken for other pathologic conditions, notably gall-bladder disease, appendicitis and upper urinary tract lesions due to ureteral obstruction from adhesions to the vesicles. Malaria and meningitis have been diagnosed when the actual lesion was vesiculitis. Bacterial organisms of various types have been cultured 


\section{BRITISH JOURNAL OF VENEREAL DISEASES}

from the vesicles, particularly $B$. coli and various cocci groups.

Gonococci and secondary organisms may live in the stagnant pool of the vesicle for long periods. Mr. Frank Kidd $^{1}$ reported one case in which the gonococci persisted twenty-five years, in another thirteen years and in still another forty-four years, and then set up attacks of arthritis and iritis through focal infection. I have seen several cases in which the infectious elements persisted for ten to twenty-two years.

Despite its serious aspects and frequency, the routine treatment of vesiculitis has not attained much success. Massage, intravesical irrigations, urethral instillations, urethroscopy, sounds, vaccines, have been employed, frequently for many months, which is a compliment to the tenacity and patience of patient and physician, but with admittedly unsatisfactory results. The underlying fact is that these measures, useful in urethral conditions, do not reach the seat of the trouble. They do not encourage or facilitate drainage and emptying of the infected sacs. An attack of epididymitis or an awakening of the latent infection elsewhere very often follows vesicular massage when the ejaculatory duct is clogged, due to the forcible manipulation of a closed sac loaded with pus and micro-organisms. It may be added that the use of irrigations, instillations and sounds without direct treatment of the source of the infection is analogous to mopping up the floor without turning off the faucet.

Routine treatment has been reinforced of late by the application of heat in the form of diathermy and pyrotherapy. Diathermy is a valuable supplementary measure after evacuation and drainage have been obtained by other means; it undoubtedly helps to destroy residual bacteria by stimulating the blood supply in the infected organs. It is still too early to determine the ultimate status of "fever therapy" and the retrograde lavage of the seminal vesicles as modified by McCarthy and Ritter. ${ }^{2}$ Certain clinical and technical objections and difficulties militate against the popular employment of these procedures.

It is my considered opinion that vasotomy offers the most effective treatment of chronic vesiculitis in the vast majority of cases. By means of it a non- 


\section{VASOTOMY}

irritant bactericide is introduced into the interior of the vesicle by way of the vas deferens and stimulates drainage by emptying the vas, vesicle and ejaculatory duct of their pathologic contents. Vasotomy should be done, always bilaterally, as soon as it becomes evident that the routine treatment is not effecting a cure.

The indications for vasotomy may be set down briefly as follows: In chronic intractable or recurrent gonorrhea with a history of posterior infection ; in low back-pain following gonorrhea; in imminent epididymitis, as a preventive of extension to the epididymis and for sterilisation of the infected vesicle; coincident with incision or puncture of the epididymis; in gonorrheal arthritis and other metastatic invasions, in which conditions vasotomy is almost a specific.

Vasotomy has a most respectable sponsorship behind it. Devised in I906, by Belfield, of Chicago, it has been employed extensively on both sides of the Atlantic, notably by Kidd, in England, Fraser, in South Africa, Luys, in France, and Valverde, in Brazil. Nevertheless, as has been pointed out, ${ }^{3}$ " there are still some urologists, most of whom have never performed vasotomy, who decry its use. Others have employed it indiscriminately and often without indication and claim the operation is of little or no use." Those, however, who have employed vasotomy in a large number of cases and have mastered its technique and indications, are strong advocates of it because of the striking results obtained.

Frank Kidd reported ${ }^{1}$ that 2 I of the 25 cases thus treated were " immediately and effectively cured within three weeks after their operation." He found "the quickness of the results is little short of miraculous." All of his cases had had months, if not years, of ordinary treatment by all known methods. He advised that " it should be done in all cases of chronic relapsing gonorrhœa (or $B$. coli and streptococcic vesiculitis) in which four to six months of treatment by massage, urethroscope, vaccines, etc., has failed to effect a cure ; also in chronic arthritis with chronic relapsing epididymitis that do not yield to such treatment.

The literature is replete with reports of a similar favourable nature. In the United States favourable reports have been made by Belfield ${ }^{4}$ (I,I43 cases), 


\section{BRITISH JOURNAL OF VENEREAL DISEASES}

Herbst and Thompson, ${ }^{5}$ Mark, ${ }^{6}$ Thomas, ${ }^{7}$ Keyes, ${ }^{8}$ Eisendrath and Rolnick ${ }^{3}$ and many others. My own experience covers slightly more than 300 cases and so far as my records and inquiries can determine, between 85 and 90 per cent. of the cases thus treated were clinically cured and have remained so for years. The most striking results were noted in cases of gonorrhœal arthritis ; they responded almost immediately.

A report of two such cases, typical of the rest, may be of interest:

Case I. A.B., aged I8, an American athlete, while participating in a tournament in Scotland, was infected with gonorrhœea, in August, I929. Although under the care of a competent physician, arthritis involving several joints developed within ten days after the onset of the infection. The arthritis and a severe antero-posterior infection were still present when he sailed for home some seven weeks later. He was kindly referred to me by his Edinburgh physician. On examination, the urine was found loaded with pus and numerous gonococci were found in the discharge. I advised, and performed, vasotomy, and within a week all of his joint symptoms had disappeared. He left New York for his home city in good condition and eventually made a complete recovery of his urethritis under the care of his local attendant. He has reported several times, feeling perfectly well and apparently non-infectious.

Case 2 (previously reported). W.H., aged 26 , referred by his physician in July, I92I. For three months he had been on his back with gonorrhœal arthritis involving both knees, which had appeared one week after the onset of his gonorrhœea. He had been treated by a local urologist with vaccines, immobilisation and other routine measures. Could not stand or walk without the aid of crutches.

On examination, the urine was moderately purulent; prostate and vesicles large and tender; both knees swollen and painful to the touch; motion impossible ; complement fixation positive.

Bilateral vasotomy was done. Improvement was. almost immediate and when he left the hospital one week after operation he was able to bend his knees for the first time in several months. Subsequent treatment of the urethra and prostate completely cured the infec- 


\section{VASOTOMY}

tion. He was last seen in January, I932, eleven years after operation, perfectly well.

That chronic vesiculitis may be mistaken for appendicitis is illustrated in the following case report :-

D.A., aged 26, was admitted to hospital in November, I922, with an indefinite diagnosis. The principal complaint was fever and general malaise. There was a history of gonorrhœe two years previously, apparently cured, but no other illness of note. As the man had come from the South, it was suspected that he had malaria, typhoid or some other endemic disease prevalent in that part of the country. Before a definite diagnosis could be made, he was seized one night with severe pain and tenderness over McBurney's point and a marked elevation of temperature. The surgeon called in consultation concluded the case was one of appendicitis and advised operation. It was planned to operate the following day, but that morning as he was being shaved preparatory to operation, the orderly noticed quite a marked purulent discharge at the meatus, which he wisely reported. As gonococci were found in the discharge, the patient was referred to my service for further study.

We found a typical chronic vesiculitis with numerous gonococci and other organisms in the expressed secretion. I recommended vasotomy in order to help clear up the diagnosis, and within three days after this was done his abdominal pain had disappeared, the temperature had returned to normal and he was feeling well. Local treatment to the urethra subsequently cleared up the urethritis and stricture, and the man remained well for ten years, when he contracted a second acute Neisserian infection, which happily was confined to the anterior urethra. He was last seen in I932, his appendix still intact.

It may be of interest to report one of many similar cases illustrating the value of vasotomy in chronic recurrent gonorrhœa :

J.D., merchant, contracted gonorrhœa in I9I3, from which he apparently recovered after several months of treatment. In I9I8 he married and later became the father of two children. In April, I930, without accountable cause, he had an acute exacerbation of the old infection. There had been no extra-marital relations 


\section{BRITISH JOURNAL OF VENEREAL DISEASES}

at any time. He was treated for six months by a competent urologist in his home city and was declared cured. On a business trip to New York some five months later he suffered a severe acute recurrence, and when he consulted me on the advice of his physician he had an acute antero-posterior infection, pain on voiding, purulent discharge loaded with gonococci, large and tender prostate and vesicles and pain in the right vas deferens, which I interpreted as the precursor of an impending epididymitis. This developed the following day. With rest in bed, diathermy and other local treatment, the epididymitis subsided in eight or nine days, and I then advised vasotomy. This was done, and two weeks later his condition was such that he left for home practically well. His physician completed the treatment of the urethritis. In these six years he has reported about twice a year, and on each occasion the cultured prostatovesicular secretion has been organism-negative and with but two or three pus-cells to the field. The last check-up was made late in February, I936, and was negative in all respects. As I look back on this case, I think an error was made in not performing vasotomy before his epididymitis developed. Later experience leads me to feel that vasotomy would have prevented the epididymitis.

I recently reported ${ }^{9}$ a number of cases in elderly men, some of whom had had gonorrhœa in earlier years, who had typical symptoms of hypertrophic prostatism. In reality, the condition was an unidentified chronic vesiculitis, which readily responded to vasotomy, with complete relief of their urinary symptoms. It has been demonstrated by Von Lackum and others ${ }^{10}$ that the so-called median bar obstruction is generally of inflammatory origin and in many of these cases can be traced back to a gonorrhœal vesicular infection. In these cases, vasotomy often results in a striking relief of the symptoms, thus avoiding prostatectomy or resection.

It goes without saying that vasotomy, though a simple procedure done under local anæsthesia and requiring but two days rest in bed, nevertheless demands the most exacting technique to insure the best results. Two factors must be strictly observed for success. The first is to be sure that the solution is injected within the lumen of the vas and not in or outside of its sheath. 


\section{VASOTOMY}

This accident is liable to occur in the hands of a careless operator and the untoward result is laid to the operation. Secondly, the solution employed may determine the success or failure of the operation. Many antiseptics. have been used, notably Collargol, Argyrol, Mercurochrome and other silver salts. Each operator has his personal preference, and it were futile to offer argument on the advantages of one over the others. I have tried all of them. One can only state his preference. Mine is a 5 per cent. solution of Argyrol, freshly made. My greatest satisfaction has been found in cases in which this solution was employed.

An irritant solution injected into the vas deferens may do considerable damage to the sensitive tissues. This is well shown in the case reported by Kile ${ }^{\mathbf{1 1}}$ and the case of gangrene of the testicle following the injection of a I per cent. solution of Mercurochrome reported by Townsend. ${ }^{12}$

It is important to remember that vasotomy will not and cannot cure cases of vesiculitis which are complicated by urethral stricture or follicles, granular urethritis or prostatitis, without additional treatment directed to these conditions, either before or after the vasotomy. "Many of the failures of vasotomy to complete a cure have not been because of the failure of the operation to clean up the infected vesicle, but because the surgeon had failed to recognise and treat the associated conditions " 5 ; and Mark concludes ${ }^{6}$ that there are too many good results reported from this procedure to cast it aside as valueless, and where unsuccessful results are reported he believes such results to be due to bad surgical judgment on the part of the operator. Fraser and Goldschmidt, ${ }^{13}$ reporting a series of successful cases, mention a type of case which must frequently pass as "typhoid," in which with the appearance of the Argyrol in the urine after vasotomy " the temperature has dropped, as it does after the evacuation of pus from an abscess." They also conclude that the occurrence of stricture of the vas after vasotomy is " to all intents and purposes negligible."

The alleged development of stricture after vasotomy is the one serious objection to the procedure most frequently heard. Obviously, strong solutions which act like caustics on the epithelial lining of the vas are much 


\section{BRITISH JOURNAL OF VENEREAL DISEASES}

more likely to cause stenosis than a mild, non-irritant solution. In a large number of my cases I have had occasion to examine the semen after operation and have found actively motile sperms in more than 80 per cent. of the cases thus examined. Unfortunately, the semen in the remaining 20 per cent. of cases was not examined before operation, so that we cannot tell how many of these men were sterile before the vasotomy. It has been my practice in more recent years to examine the semen, whenever it was possible, before operation; as a result I find that the cases which develop stenosis and azoospermia are very rare. Cumming ${ }^{14}$ examined II3 men after bilateral vasotomy and found motile sperms in every case; Ross ${ }^{15}$ concluded that occlusion of the vas is not a uniform sequel of operation; and Belfield ${ }^{4}$ found sperms in the semen of 8 men who had but one functioning testicle in whom he had done vasotomy. It must be quite evident from the available data that there is but little ground for the belief that vas occlusion inevitably follows vasotomy, when properly performed. This objection to vasotomy is usually raised by men who have had no experience of the operation themselves.

In some of my cases men who had been sterile (by test) before operation because of inflammatory occlusion of the vas or ejaculatory duct, or both, have had the sterility removed by the vasotomy, much to their chagrin, because they are now subject to the biologic and economic consequences of their philandering. It is the part of wisdom, however, to warn patients of the possibility of sterility following vasotomy; but very few men reject the operation on that account, in the sensible belief that they (as well as the community generally) are better off sterile than infectious.

In my series of cases two complications developed, both due to faulty technique. In one instance, a hematoma formed in the scrotum due to failure to tie off a fine oozing blood vessel ; in the second, the wall of the vas was punctured by the ragged edge of a filed-off needle, with the result that some of the injected solution entered the scrotal cavity before the leakage was discovered. A local irritation developed, which passed off without serious consequences.

These views on vasotomy may be summarised by quoting the conclusions of the master, Belfield, in which 


\section{VASOTOMY}

I fully concur : (I) Vasotomy terminates non-tuberculous infection, acute or chronic, in ampulla or vesicle in a large majority, at least 80 per cent. ; (2) it never causes impotence; it may cause sterility, but only through lack of knowledge or skill in the operator; when so caused, it usually can be removed by resection of the vas ; (3) that no major operation (vesiculotomy or vesiculectomy) should be performed merely for the cure of vesicular infection until vasotomy has been done and has failed. I might add a fourth, namely, that vasotomy (bilateral) should be done in every case as soon as it is seen that four or five months of routine treatment has failed to effect a cure.

\section{REFERENCES}

(I) KIDD, Frank : Lancet, August 4th, I923, 205, No. 52I4, p. 2 I3.

(2) McCarthy, J. F., and Ritter, J. S. : Jour. Am. Med. Assn., 98, p. 687 .

(3) “Text-Book of Urology," D. N. Eisendrath and H. C. Rolnick, I928, J. B. Lippincott \& Co., p. 369.

(4) Belfield, W. T. : Journal of Urology, October, I925, 14, No. 4, p. 349 .

(5) Herbst, R. H., and Thompson, A.: Ill. Med. Jour., September, I 220,38 , No. 3, p. 2 I2.

(6) MARK, E. G. : Journal of Urology, October, I925, 14, No. 4, p. 323.

(7) Thomas, B. A.: Journal of Urology, October, I925, 14, No. 4, p. 33I.

(8) Keyes, E. L. : “Urology,” I928, D. Appleton \& Co., p. I95.

(9) Wolbarst, A. L.: Med. Rec., April 3rd, I935, 141, No. 7, p. 3 I9.

(io) Von Lackum, W. H., and Mitchell, J. I. : Journal of Urology, July, I939, 22, No. I, p. 76.

(II) KILe, R. P.: Urol. and Cut. Rev., February, I924, 28, No. 2, p. 66.

(I2) Townsend, J. M. : Urol. and Cut. Rev., August, I935, 39, No. 8, p. 553.

(I3) Fraser, A. R., and Goldschmidt, L. B. : Lancet, October 9th, I926, 211, No. 5380, p. 749 .

(I4) Cumming, R. E. : Urol. and Cut. Rev., February, I934, 28, No. 2, p. 65 .

(I5) Ross, W. L., Jr. : Journal of Urology, August, I924, 12, No. 2, p. I38. 